\title{
Analysis and optimization of coagulation and flocculation process
}

\author{
V. Saritha $\cdot$ N. Srinivas $\cdot$ N. V. Srikanth Vuppala
}

Received: 20 May 2014/ Accepted: 19 December 2014/Published online: 1 February 2015

(C) The Author(s) 2015. This article is published with open access at Springerlink.com

\begin{abstract}
Natural coagulants have been the focus of research of many investigators through the last decade owing to the problems caused by the chemical coagulants. Optimization of process parameters is vital for the effectiveness of coagulation process. In the present study optimization of parameters like $\mathrm{pH}$, dose of coagulant and mixing speed were studied using natural coagulants sago and chitin in comparison with alum. Jar test apparatus was used to perform the coagulation. The results showed that the removal of turbidity was up to $99 \%$ by both alum and chitin at lower doses of coagulant, i.e., $0.1-0.3 \mathrm{~g} / \mathrm{L}$, whereas sago has shown a reduction of $70-100 \%$ at doses of 0.1 and $0.2 \mathrm{~g} / \mathrm{L}$. The optimum conditions observed for sago were 6 and 7 whereas chitin was stable at all $\mathrm{pH}$ ranges, lower coagulant doses, i.e., $0.1-0.3 \mathrm{~g} / \mathrm{L}$ and mixing speed-rapid mixing at $100 \mathrm{rpm}$ for $10 \mathrm{~min}$ and slow mixing $20 \mathrm{rpm}$ for $20 \mathrm{~min}$. Hence, it can be concluded that sago and chitin can be used for treating water even with large seasonal variation in turbidity.
\end{abstract}

Keywords Chitin $\cdot$ Sago $\cdot$ Mixing speed $\cdot$ Coagulation and Flocculation

V. Saritha $(\bowtie) \cdot$ N. Srinivas $\cdot$ N. V. Srikanth Vuppala Department of Environmental Studies, GITAM Institute of Science, GITAM University, Visakhapatnam 530 045, India e-mail: vsjr08@gmail.com

\section{Introduction}

Because of its ability to solubilise, pure water is not found in nature. Dissolved impurities comprise minerals, organic compounds and gases that alter the physical (turbidity, color, temperature, electrical conductivity), chemical (chemical and biological demand for oxygen, $\mathrm{pH}$, alkalinity, total organic carbon) and biological characteristics of water, whose effect depends on the composition, concentration and chemical reactions between pollutants (Richter 2009; Theodoro et al. 2013).

Safe drinking water is essential to the health and welfare of a community and water from all sources must have some form of purification before consumption. Various methods are used to make water safe and attractive to the consumer. The method employed depends on the character of the raw water. One of the problems with treatment of surface water is the large seasonal variation in turbidity (McConnachie et al. 1999).

The efficiency of suspended solid (colloid) separation from water has been achieved by the application of chemical coagulants such as alum, ferric chloride, and polyelectrolyte. This process highlights a water treatment mechanism that stimulates the aggregation of suspended particles to settleable flocs by the destabilization of the charged colloids thus, neutralizing the forces that keep them apart. The factors that influence coagulation-flocculation are, among others, temperature, $\mathrm{pH}$, effluent quality, dosage and coagulant type (Nnaji 2012; Jin 2005; Ma et al. 2001).

The suspended particles vary considerably in source, composition charge, particle size, shape, and density. Correct application of coagulation and flocculation processes and selection of the coagulants depend upon understanding the interaction between these factors. It is 
imperative for relevant stakeholders to fully comprehend the technicalities involved when considering the coagulants for rural domestic water treatment.

Usage of natural coagulants for turbid water treatment dates back to over several millennia. So far, environmental scientists have been able to identify several plant types for this purpose. While it is understandable that these coagulants are meant as simple domestic point of use (POU) technology, there have also been numerous studies focused on their usage for treatment of industrial wastewaters. The mechanisms associated with different natural coagulants are varied as well (Babu and Chaudhuri 2005).

To address these issues, the present work focuses on the understanding and optimisation of various factors that govern the process of coagulation by natural coagulants, so that environmental experts can tailor its usage for copious water contaminants. The coagulants nominated in this study are a plant-based coagulant, sago and the other derived from non-plant source chitin (widely produced from exoskeleton of crustaceans).

\section{Methodology}

The work has been intended and implemented based on three stages.

\section{Optimization of coagulant dosage}

The study was initialized by testing the efficiency of the coagulants in removal of turbidity. The results from this stage of study encouraged us to proceed further to second stage, with the coagulant dosage optimized at $0.1,0.2,0.3$ and $0.4 \mathrm{~g} / \mathrm{l}$.

\section{Optimization of $\mathrm{pH}$}

The optimized dosages of coagulants were further examined at various $\mathrm{pH}$ conditions to test their efficiency and suitability at a wide range of $\mathrm{pH}$. The observations from the study revealed the optimum $\mathrm{pH}$ conditions to be 6,7 and 8 .
Optimization of mixing speed and time

Coagulation is performed in two stages: first the coagulant is rapidly mixed and then flocculation is enhanced by slow mixing. Hence, the optimized dosages were further optimized for varied mixing speed and time for each stage of coagulation.

Further the studies were extended with the following optimized parameters obtained from the above studies: $\mathrm{pH}-6,7$ and 8; Coagulant dosage- $-0.05,0.1,0.15$ and $0.2 \mathrm{~g} / 500 \mathrm{ml}$; Mixing speed-rapid mixing at 100 mixing speed for $10 \mathrm{~min}$ and slow mixing at 30 mixing speed for $20 \mathrm{~min}$; rapid mixing at 80 for $2 \mathrm{~min}$ and slow mixing at 20 for $20 \mathrm{~min}$.

Natural coagulants

Sago

Tapioca is a productive crop in poor soils and requires the least labor in cultivation and can tolerate drought, but the labor requirement in processing after harvest is high (Radhakrishnan 1996). Indian sago starch is extracted from Manihot esculenta belonging to family Euphorblaceace. It is also known as SAGO (SABUDANA in Hindi or JAVVARISHI in Tamil). This sago is native to Brazil, Amazon, Colombia, Venezuela, West Indies, Cuba, and Puerto Rico. In India it was introduced in later part of nineteenth century. Kerala, Andhra Pradesh and Tamil Nadu are the major producers of sago starch (Sabuindia 2013; Renu and Garima 2013). Dry tapioca root consists of $80-90 \%$ carbohydrate out of which the most important is starch. Starch content in tapioca ranges from 78.1 to $90.1 \%$ on dry basis. Tapioca is mainly processed into starch and sago. There are more than 1,000 tapioca processing units in India producing starch and sago in cottage and small scale sectors (Manickavasagan and Thangavel 2006). 

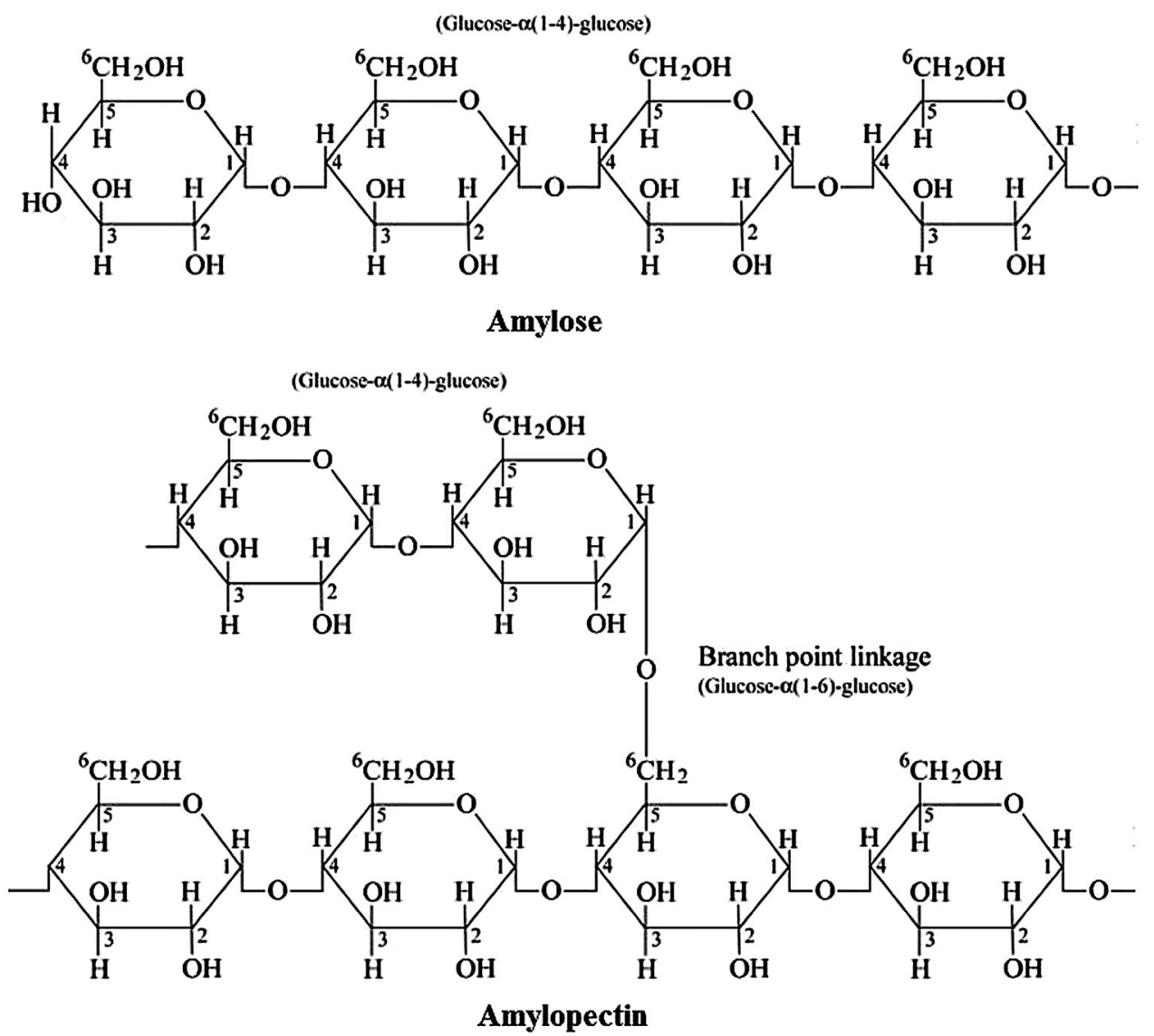

Chemical structure of (starch) amylose and amylopectin (Buleon et al. 1998)

\section{Chitin}

Like cellulose, chitin is a fiber, and in addition, it presents exceptional chemical and biological qualities that can be used in many industrial and medical applications. Chitin is one of the most abundant renewable biopolymer on earth that can be obtained as a cheap renewable biopolymer from marine sources (Feisal and Montarop 2010). It is biocompatible, biodegradable and bio-absorbable, with antibacterial and wound-healing abilities and low immunogenicity; therefore, there have been many reports on its biomedical applications (Muzzarelli 1977).

Chitin is a long-chain polymer of $\mathrm{N}$-acetyl glucosamine, a derivative of glucose, and is insoluble in water due to its intermolecular hydrogen bonds (Minke and Blackwell 1978). One of their most important features is the ability (flexibility) to be shaped into different forms such as fibers, hydrogels, beads, sponges, and membranes (Mano et al. 2007). The origin of chitin affects its crystallinity, purity, polymer chain arrangement, and dictates its properties (Rinaudo 2006).

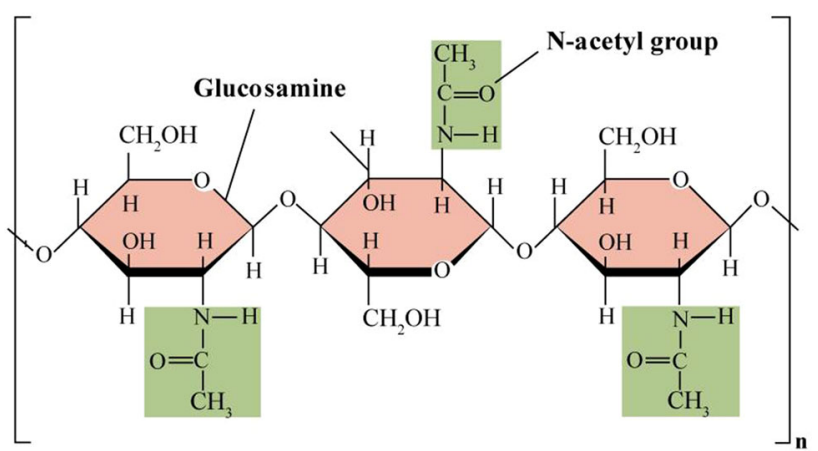

Structure of chitin

\section{Collection of samples}

For the present study the surface water samples were collected from two different sources in and around Visakhapatnam, i.e., Mudasarlova and P.M. Palem. Care was taken while collecting the samples so that a representative sample is obtained. All samples were collected in sterile plastic containers. The samples were transported to the laboratory 
Table 1 Analytical methods

\begin{tabular}{lll}
\hline Parameter & Measurement & Unit \\
\hline $\mathrm{pH}$ & Electrical pH meter & \\
Turbidity & Nephelo turbidimeter & $\mathrm{NTU}$ \\
Conductivity & Electrical conductivity meter & $\mathrm{mmohs}$ \\
Color & Spectrophotometer & $\mathrm{Pt}-\mathrm{Co}$ \\
Total hardness & Titrimetry analysis & $\mathrm{mg} / 1$ \\
Calcium hardness & Titrimetry analysis & $\mathrm{mg} / 1$ \\
Alkalinity & Titrimetry analysis & $\mathrm{mg} / 1$ \\
Chlorides & Argentometric method & $\mathrm{mg} / 1$ \\
\hline
\end{tabular}

and all the experiments conducted within duration of $24 \mathrm{~h}$. Temperature was noted at the point of sample collection. The water samples were subjected to the following parameters both pre- and post-treatment with the two coagulants (Table 1).

Determination of sample color was done using absorbance reading and standard curve relating absorbance and CU. $\mathrm{pH}$ was determined using a $\mathrm{pH}$ electrode which was calibrated with two standard buffer solutions of $\mathrm{pH} 4.0$ and 9.2. The conductivity was determined using a conductivity cell which was calibrated with standard $0.1 \mathrm{~N} \mathrm{KCl}$ solution of conductivity $14.12 \mathrm{mmhos}$ at $30^{\circ} \mathrm{C}$. Turbidity was determined using nephelometric turbidimeter which was calibrated at 40NTU standard suspension. Alkalinity was determined by titrimetric method using standard $0.02 \mathrm{~N}$ $\mathrm{H}_{2} \mathrm{SO}_{4}$. Chloride was estimated by argentometric method by titrating against $0.0141 \mathrm{~N} \mathrm{AgNO}_{3}$. Solids were determined gravimetrically. Hardness was determined by EDTA method.

The specifications of Jar test apparatus used for coagulation are as follows:

Made: Cintex flocculator; model: CIC-30; size: $10^{\prime \prime} \times 24^{\prime \prime} \times 32^{\prime \prime}$; display: digital $12 \mathrm{~mm}$ red LED display for RPM; speed: common, variable from 5 to 160 with accuracy of $\pm 1 \mathrm{RPM}$; capacity: suitable for $1,000 \mathrm{ml} \times 4$ No's; illumination: fluorescent tubes; dimension: D $250 \mathrm{~mm} \times \mathrm{H} 560 \mathrm{~mm} \times \mathrm{W} 790 \mathrm{~mm}$; power supply: $230 \mathrm{v} \pm 10 \%$ Ac. $50 \mathrm{~Hz}$.

\section{Result}

Color is reduced up to $90 \%$ with alum at $\mathrm{pH} 7$ at both mixing speed whereas chitin reduced more than $92 \%$ at the same $\mathrm{pH}$ at both mixing speed at all doses. With sago color reduction was in the peak with $99.93 \%$ in both the mixing speeds, Fig. 1.

At $100-30$ mixing speed turbidity reduction was maximum (53.85-100\%) at $\mathrm{pH} 6$ for all doses of sago comparatively with 80-20 mixing speed which showed maximum reduction (53.85-100\%) at $\mathrm{pH}$ 7. Turbidity reduction is good at $\mathrm{pH} 7$ at both mixing speed (100-30 and $80-20$ ) and in $\mathrm{pH} 8$ only at $100-30$ mixing speed by alum at all four doses but chitin showed a stability in reduction of turbidity in all the $\mathrm{pH}$ at both mixing speed at 0.05 and 0.10 doses which is more than $93 \%$, Fig. 2 .
Fig. 1 Color removal efficiencies of the three coagulants

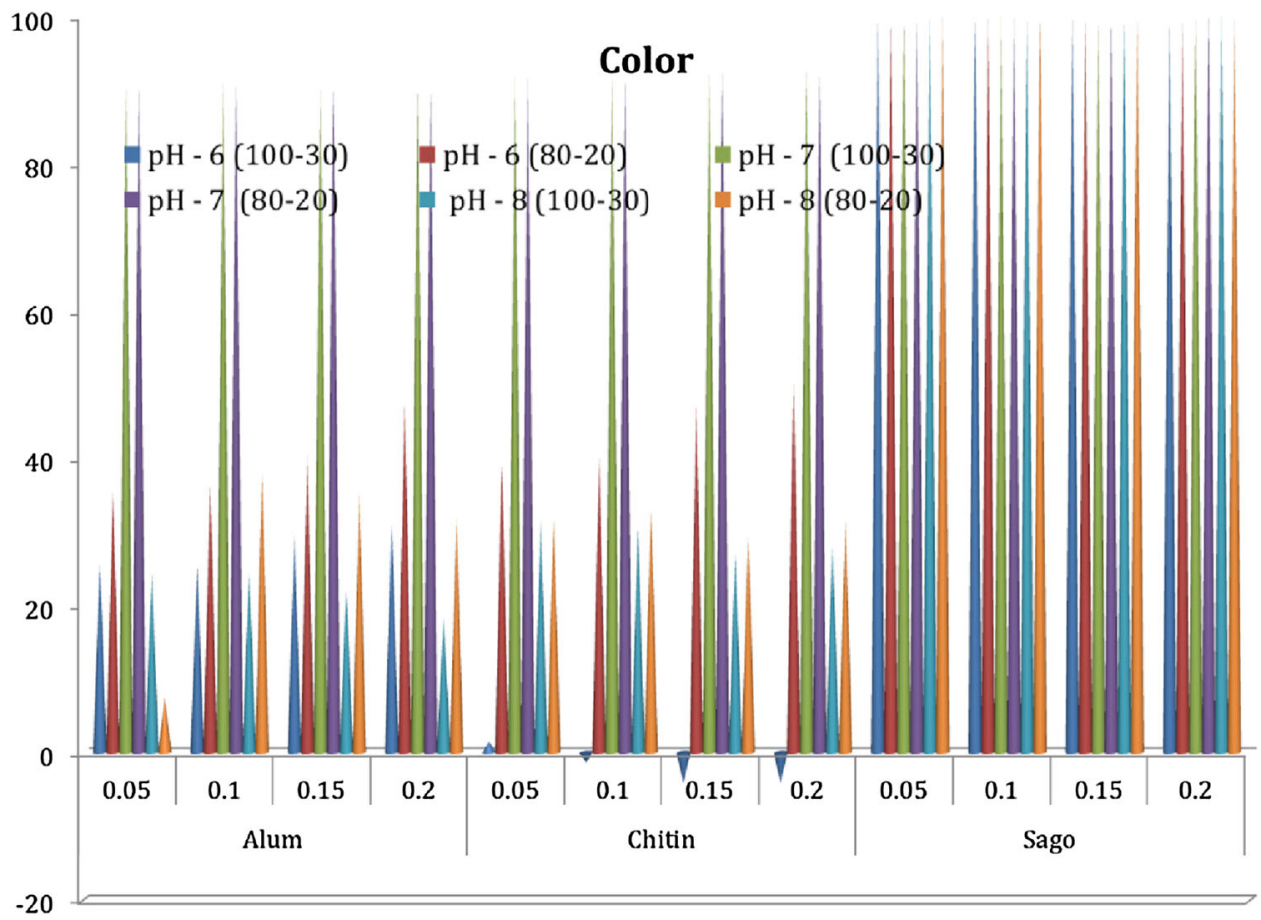


Fig. 2 Turbidity removal efficiencies of the three coagulants

\section{Turbidity}

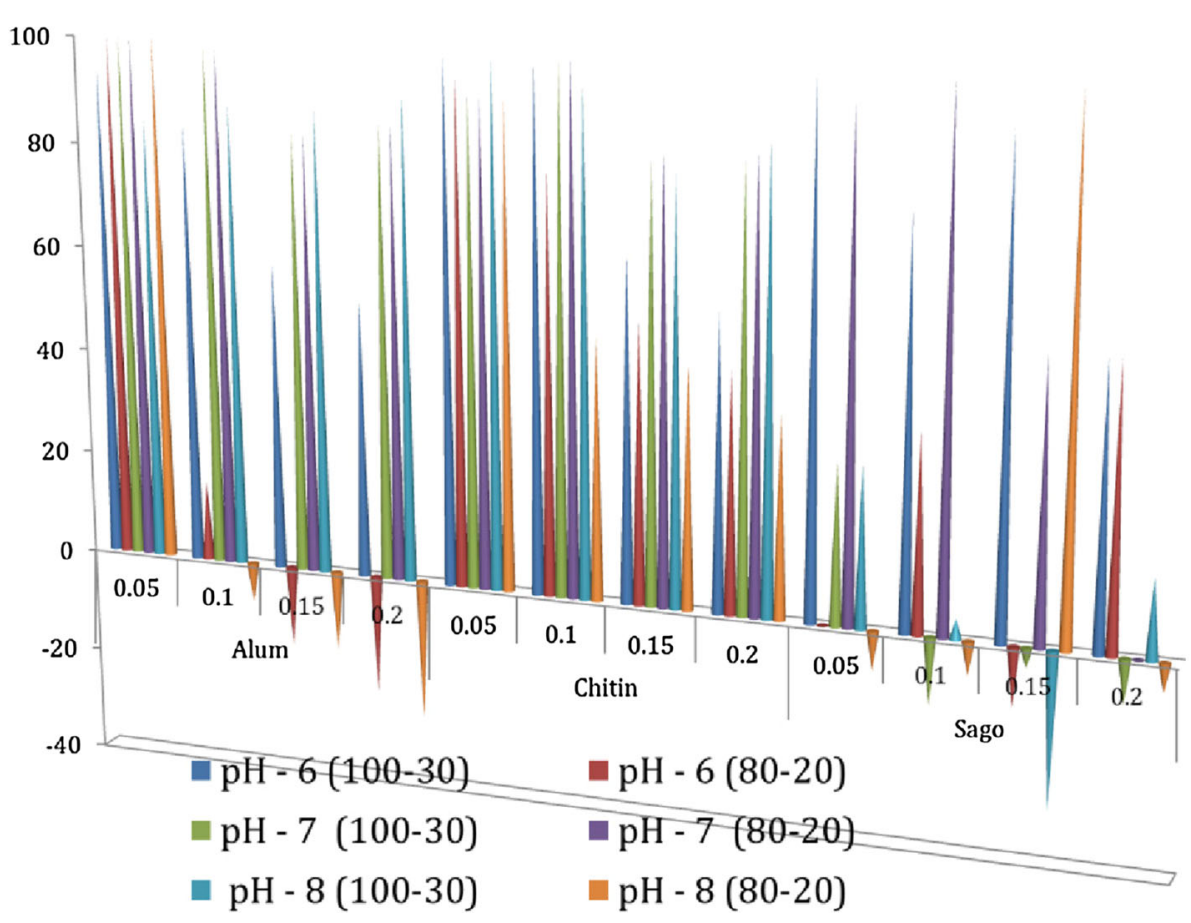

Fig. 3 Alkalinity removal efficiencies of the three coagulants

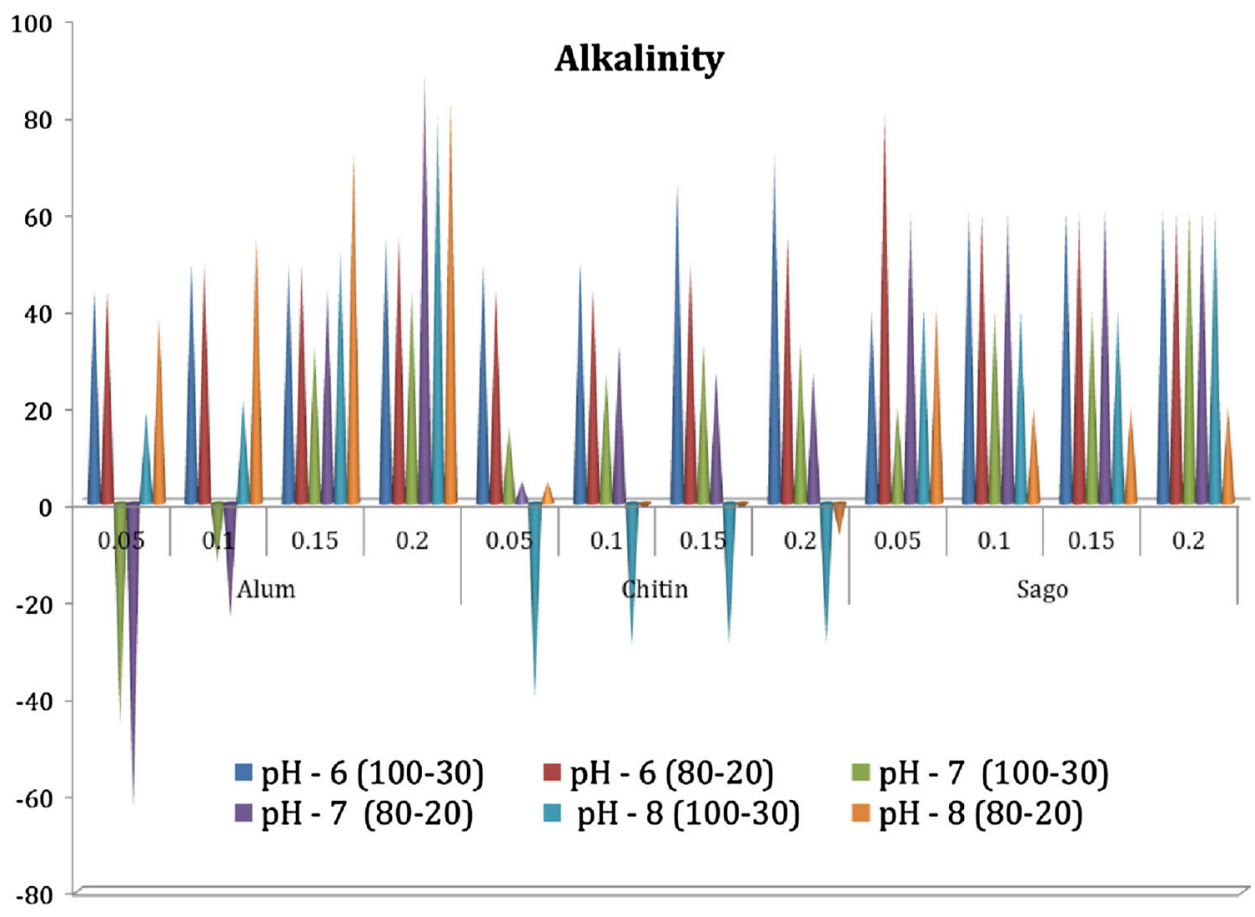

Alkalinity was also removed adequately at the higher mixing speed at $\mathrm{pH} 6(80 \%)$, by sago at lower concentrations, whereas decrease in alkalinity is $80 \%$ with alum at only 0.20 doses at $\mathrm{pH} 7$ at mixing speed 80 and 20 and at $\mathrm{pH} 8$ with both mixing speed. Chitin has succeeded to decrease alkalinity at both $\mathrm{pH} 6$ and $\mathrm{pH} 7$ in all the doses, Fig. 3.

The removal of chloride was perceived to be noble at $\mathrm{pH}$ 7 with mixing speed of 80-20 (78.57\%) by sago on the other hand alum and chitin both are good in reduction of 
Fig. 4 Chloride removal efficiencies of the three coagulants
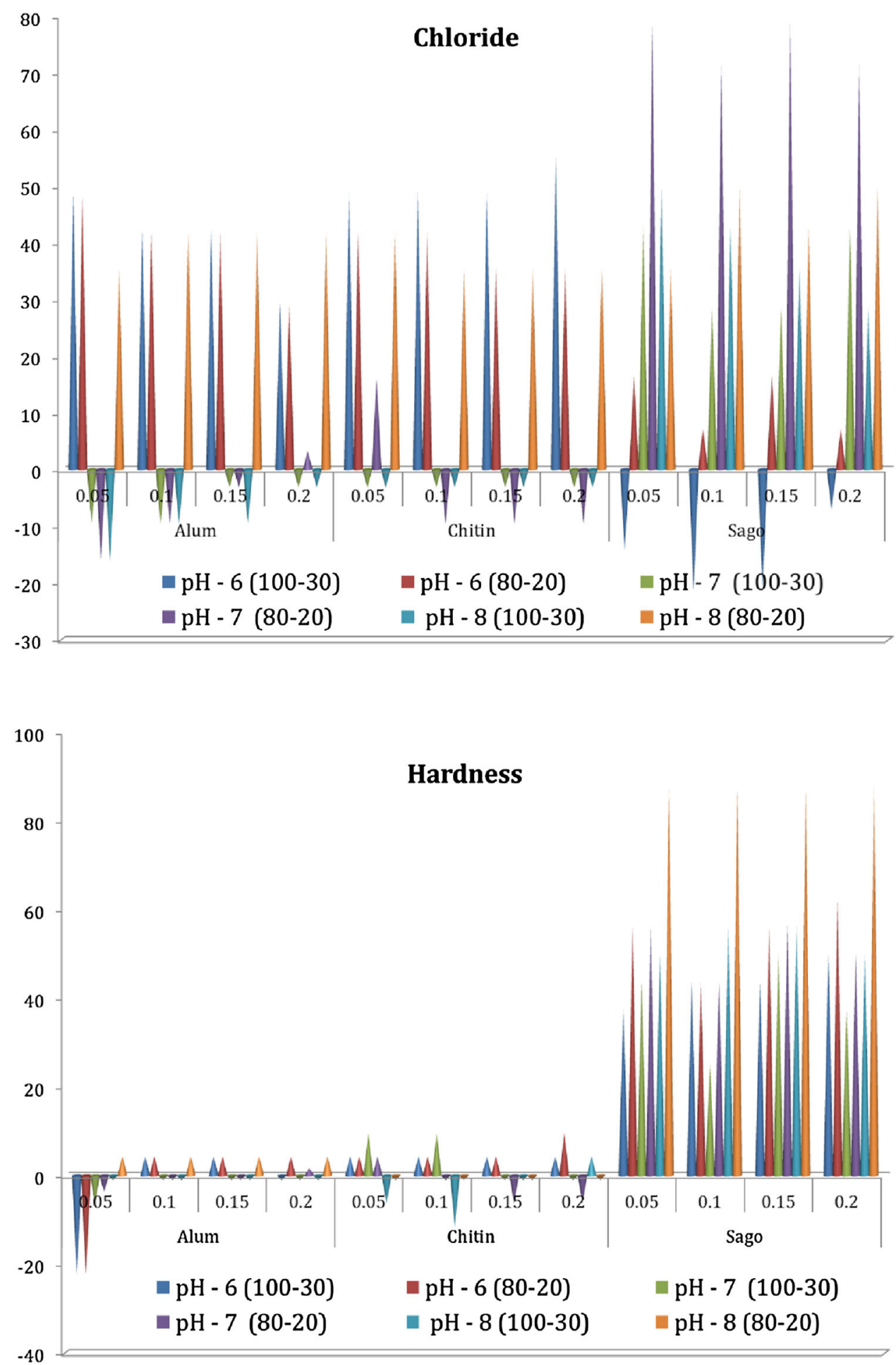

Fig. 5 Hardness removal efficiencies of the three coagulants chlorides by $48 \%$ at $\mathrm{pH} 6$ in both mixing speed at all doses, Fig. 4. It is observed that total hardness reduction is good with chitin at $\mathrm{pH} 6$ with both mixing speeds. In fact, hardness removal was good at the same mixing speed with pH $8(87.5 \%)$ by sago, Fig. 5. All the results obtained were in limits according to the Indian Drinking Water Standards given in Table 2.

\section{Discussion}

Turbidity can change the organoleptic properties of water. It can also provide food and shelter for pathogens in the distribution system leading to waterborne diseases (Mackenzie and Cornwell 1991). The coagulation flocculation is considered the most important process in water surface 
Table 2 Indian standard specifications for drinking water IS: 10500

\begin{tabular}{lllll}
\hline S.No & Parameter & Measurement & Unit & Requirement desirable Limit \\
\hline 1 & $\mathrm{pH}$ & Electrical pH meter & & $6.5-8.5$ \\
2 & Turbidity & Nephelo turbidimeter & $\mathrm{NTU}$ & 10 \\
3 & Conductivity & Conductivity meter & $\mathrm{mmohs}$ & - \\
4 & Color & Spectrophotometer & $\mathrm{Pt}-\mathrm{Co}$ & 5 \\
5 & Total hardness & Titrimetry analysis & $\mathrm{mg} / \mathrm{l}$ & 300 \\
6 & Calcium hardness & Titrimetry analysis & $\mathrm{mg} / \mathrm{l}$ & 75 \\
7 & Alkalinity & Titrimetry analysis & $\mathrm{mg} / \mathrm{l}$ & 200 \\
8 & Chlorides & Argentometric method & $\mathrm{mg} / \mathrm{l}$ & 250 \\
\hline
\end{tabular}

treatment. Coagulation allows by the injection and the scattering of chemical (coagulants) during relatively intense mixing to destabilize naturally occurring particles and macromolecules and/or to precipitate additional particles (Mackenzie and Cornwell 1991).

Flocculation permits, by the addition of synthetic or natural polymers in slant of slow mixture, to promote the aggregation and bind together the micro-flocs of destabilized particles into larger flocks that can be removed subsequently by sedimentation and/or filtration.

Recently, the use of environmentally friendly coagulants is widened. They can be proposed as an important alternative for water treatment. Natural organic polymers named biopolymers are naturally produced or extracted from animals, plant tissues or microorganisms. These biopolymers are not toxic for human health and are biodegradable. Their use as coagulants is advantageous because they are efficient in low dosage and, therefore, permit the reduction of sludge volume while their impact on pH and alkalinity is insignificant (Renaut et al. 2009).

\section{Optimization of $\mathrm{pH}$}

The $\mathrm{pH}$ will not only affect the surface charge of coagulants, but also affects the stabilization of the suspension. Besides, the solubility of chitin in aqueous solution is influenced by $\mathrm{pH}$ value. Therefore, the study of $\mathrm{pH}$ was essential to determine the optimum $\mathrm{pH}$ condition of the treatment system. The effectiveness of alum, commonly used as a coagulant, is severely affected by low or high $\mathrm{pH}$. In optimum conditions, the white flocs were large and rigid, and settled well in less than $20 \mathrm{~min}$. The reduction of turbidity and other parameters was observed to be good at $\mathrm{pH}$ 7. The results were in correlation with the studies done by Bina et al. 2009. This finding is in agreement with other studies at optimum pH (Ebeling et al. 2003). The optimum pH was 7 and was similar to the obtained results by $\mathrm{Di}-$ vakaran (Divakaran and Pillai 2002).

The best performance of alum was observed at $\mathrm{pH} 7$ over the selected range of turbidity but its performance decreased to some extent at $\mathrm{pH}$ values of 6 and 8. Coagulation efficiency of alum at $\mathrm{pH} 6$ was almost close to that of at $\mathrm{pH}$ 7. The highest turbidity removal was attained at $\mathrm{pH} 7$.

The relationship between the optimum dosage, $\mathrm{pH}$ and turbidity reduction value shows that the optimum dosage of chitin with respect to reduction in turbidity is smaller in acidic solutions. This phenomenon can be attributed to the increase in number of protonated amine groups on chitin at lower pH. Similar results were obtained when chitosan is used as a coagulant by Jill et al. 1999, in their experiments where they stated that the destabilization of particles was enhanced by the increase in charged groups followed by charge neutralization, resulting in a decrease in optimum dosage.

Turbidity removal is observed at lower $\mathrm{pH}$, the resulting floc diameter is smaller, accompanied by a slower settling velocity. This may be explained by the variation in the configuration of chitosan. In neutral solutions, because of the more coiled structure, the chitosan polymer is able to produce larger and denser flocs. In acidic solutions, it becomes a more extended chain (more charged), and, therefore, produces smaller and looser flocs. Moreover, the effect of $\mathrm{pH}$ on the coagulation efficiency of chitosan is insignificant. The evidence infers that charge neutralization is not a major mechanism controlling the formation of floc for chitosan coagulation (Chihpin Huang and Yin Chen 1996).

The color removal patterns of both alum and chitin were observed to be good at neutral $\mathrm{pH}$, further more chitin has shown moderate efficiency in removing color at both the acidic and basic pH ranges, i.e., at pH 6 and also 8. This may be as a result of resuspension of solids at this concentration. Furthermore, the high concentrations (>30.0 $\left.\mathrm{g} \mathrm{L}^{-1}\right)$ of the coagulant may confer positive charges on the particle surface (a positive-zeta potential), thus redispersing the particles (Amuda et al. 2006).

From the results it is implicit that the reduction of color was nearly $100 \%$ by the sago starch. A study by Di Frollini and Bernard (2000) using corn starch and cationic 
waxy cassava (essentially $100 \%$ amylopectin), and cationic synthetic polymer, demonstrated that cationic waxy cassava starch was more efficient than the other two polymers in removing turbidity and apparent color, the settling velocities studied. Furthermore, the cationic corn starch generated better results than those obtained with the cationic synthetic polymer. The authors attribute the good results obtained with the cationic tapioca starch for its high molecular weight, and mechanisms of action have been the predominant adsorption and bridging.

It was also found that the reduction of alkalinity by chitin was quite moderate to low at $\mathrm{pH} 6$ and 7 and the alkalinity was observed to be increased at $\mathrm{pH} 8$. The high content of amine groups in chitin provides cationic charge at acidic $\mathrm{pH}$ and can destabilize colloidal suspension to promote the growth of large, rapid-settling floc that can then flocculate (Roussy et al. 2005). Because it is a longchain polymer with positive charges at natural water $\mathrm{pH}$, it can effectively coagulate natural particulate and colloidal materials, which are negatively charged, through adsorption, charge neutralization, inter-particle bridging as well as hydrophobic flocculation (Li and Kegley 2005).

Alkalinity variations were observed to be moderate when treated with sago starch. In terms of action on the physico-chemical characteristics of the clarified water, the natural polymers and coagulants show or cause little variation in $\mathrm{pH}$, alkalinity, conductivity and concentration of cations and anions. Being from natural sources, these compounds can generate value-added products, presenting itself as a new source of income. In general, the natural polymers have efficiency in removal of turbidity of water, comparable or superior to that achieved by metal coagulants, spending a lower dosage. These products proved to be not dependent on temperature or $\mathrm{pH}$ correction and alkalinity of the water to work efficiently (Theodoro et al. 2013).

Based on the results it is found that chitin has not considerable potential to be used in the treatment of hard waters, especially in medium and high turbidities. It can be seen that the removal of hardness decreased with increasing hardness values (Bina et al. 2009). The presence of bivalent cations such as $\mathrm{Ca}^{+2}$ and $\mathrm{Mg}^{+2}$ increased the ion strength of solution and the destabilization. Chitin fibers absorb calcium ions very selectively, forming a chelate. The amide groups involvement is very clear, and the hydroxy groups [either the $\mathrm{C}(6)$ or the $\mathrm{C}(2)$ ] has been suggested to participate too. The selectivity seems to be caused by the chelation mechanism (Zikakis 1984). Hence, the optimum $\mathrm{pH}$ for alum was found to be 7 , whereas chitin was substantially stable at all the given $\mathrm{pH}$ ranges.

The removal of total solids in the present study was up to a maximum of $70 \%$ which correlates with the studies performed by Hasçakir (2003). Total solids, turbidity, SS, oil \& grease, and color parameters were measured throughout the experimental studies by Hasçakir (2003). Coagulation-flocculation-sedimentation (CFS) with starch in their studies has shown that treatment performances are poor in general except oil and grease removals for domestic wastewater. They have achieved almost $100 \%$ oil and grease removal for domestic wastewater as a result of the CFS process with starch.

\section{Optimization of mixing time}

In coagulation process, rapid mixing is used to spread out the coagulant throughout the turbid water. In flocculation process, slow mixing is a key part to get most favorable performance. Adequate time must be provided to allow production of particles of sufficiently large size to permit their efficient removal in sedimentation process (Wang et al. 2005). The time of macrofloc formation (flocculation time) is one of the operating parameters that is given great consideration in any water treatment plant that involves coagulation-flocculation operations.

The turbidity reduction was observed to be prodigious at high rpm, i.e., $100-30 \mathrm{rpm}$ at all $\mathrm{pH}$ ranges. The results were in correlation with the studies done by Jadhav and Mahajan 2013. In their studies substantial reduction of residual turbidity was achieved by S.S-g-PAml. The performance of S.S-g-PAml was found to be good as compared to liquid alum with the advantages of the biodegradability of S.S-g-PAml as well as less dosage of S.S-g-PAml used as compared to liquid alum (Qudsieh and Isam Yassin 2006).

\section{Effect of coagulant dose}

Coagulation dosage is one of the most important factors that have been considered to determine the optimum condition for the performance of coagulants in coagulation and flocculation. Essentially, insufficient dosage or overdosing would result in the poor performance in flocculation. Therefore, it is significant to determine the optimum dosage to minimize the dosing cost and sludge formation and also to obtain the optimum performance in treatment (Patel and Vashi 2013).

The optimum alum dosage was lower $\left(1 \mathrm{~g} \mathrm{~L}^{-1}\right)$ which was the lowest required dosage obtained the highest turbidity removal. The best performance of alum in removing turbidity from water was obtained at $\mathrm{pH} 7$ following by $\mathrm{pH}$ 6 . The coagulation efficiency of alum remained almost constant within the dosage range of $1-4 \mathrm{~g} \mathrm{~L}^{-1}$ at $\mathrm{pH}$ range of 6-8. In other words, results showed that alum dosage range for good coagulation was almost wide in this study. However, overdosing was observed for low to medium turbidity waters when $5 \mathrm{~g} \mathrm{~L}^{-1}$ alum was used. 
The results were in agreement with the report by $\mathrm{Yu}$ kselen and Gregory 2004. Turbidity removal efficiency was slightly decreased by increasing alum concentration from 40 to $50 \mathrm{mg} \mathrm{L}^{-1}$, e.g., turbidity removal decreased from 97.1 to $95.7 \%$ at $\mathrm{pH} 6$ (initial turbidity of $100 \mathrm{NTU}$ ). This reduction may be attributed to charge reversal and destabilization of colloidal particles due to overdosing as also suggested by Yukselen and Gregory (2004).

Generally, aluminum and iron salts are rapidly hydrolyzed in water to give a range of products including cationic species which can be absorbed by negatively charged particles and neutralize their charge. This is one mechanism whereby particles can be destabilized, so that flocculation can occur. Overdosing can disrupt this phenomenon, therefore, fairly precise control of coagulant dosage should be considered in water treatment plants. Results indicated that turbidity removal efficiency was varied by $\mathrm{pH}$, alum dose and initial turbidity of water. The obtained results are in accordance with those obtained by Volk et al. (2000).

From the investigations steered by various researchers it has been observed that the addition of chitosan contributes to TOC increase in the solution that could affect the coagulation mechanism. According to the experiments by Bina et al. 2009 in their studies taking into account the low dosage of chitosan in these experiments (systematically less than $1 \mathrm{mg} / \mathrm{L}$ ), the amount of organic carbon introduced would remain low enough (less than $0.8 \mathrm{mg} / \mathrm{L}$ ) to make its contribution negligible on the coagulation-flocculation performance. The results showed that chitosan could be used as natural coagulant aid for drinking water treatment.

\section{Conclusion}

Environmental requirements are becoming highly important in today's society, since there is an increased interest in the industrial use of renewable resources such as starch and chitin considerable efforts are now being made in the research and development of polysaccharide derivatives as the basic materials for new applications. In particular, the increasing costs of conventional adsorbents undoubtedly make polysaccharide-based materials one of the most attractive biosorbents for wastewater treatment. Recent and continuing interest in these macromolecules is evident from the number of papers that appear each year in the literature on this topic (Blackburn 2004; Guibal 2004).

The jar test experiments were performed on surface waters with turbidity. The coagulation experiments using aluminum sulfate, chitin and sago indicated that coagulation process effectively removed turbidity from water using $0.1-0.4 \mathrm{~g} \mathrm{~L}^{-1}$ of the used coagulants. The optimum $\mathrm{pH}$ range for turbidity removal was found to be 7 for alum and 6-8 for chitin, respectively, resulting in the maximum turbidity removal.

In general the reduction in other physico-chemical parameters was very good with alum at only $\mathrm{pH} 7$ but chitin and sago were quite constant and proficient at the varied $\mathrm{pH}$ ranges of 6-8. Investigating the influence of mixing speed on trends of turbidity removal by alum chitin and sago, the results have shown that the ability of chitin and sago can be used in wide range of $\mathrm{pH}$ and at higher mixing speed conditions.

Moreover, the effect of $\mathrm{pH}$ on the coagulation efficiency of chitin is insignificant. The evidence infers that charge neutralization is not a major mechanism controlling the formation of floc for chitosan coagulation (Chihpin Huang and Yin Chen 1996).

Starch flocculants have a series of virtues such as nontoxicity, abundance in resources, low price and biodegradability. In recent years, people had paid high attention to develop and apply it in treating water. But in practice, complexes of polyacrylamide and $\mathrm{Al}_{2}\left(\mathrm{SO}_{4}\right)_{2}$ is mainly used in water flocculation because of its good flocculation performance and low dosage. Environmentally friendly chemicals should be chosen for the treatment of wastewater. Therefore, in this study starch is selected for the treatment of surface water. During the study the new, natural, easily available and environmentally friendly product is used as coagulant and flocculant.

Hence, it is concluded that chitin and sago have properties that are of interest in water treatment. Chitin is a remarkable chelating agent and heavy metal trap. It has the ability to coagulate a variety of small particles including colloidal size particles and can even be used to destabilize many oil emulsions to aid in separating oil from water (http://www.aces.edu). Starch offers certain advantages such as availability (easy to obtain), cost, neutral pH conditions, etc., thus, makes their uses reasonable. However, despite all the associated benefits, natural coagulants and polymers should be effectively applied to the process of water clarification in scale only after undergoing tests certifying its non-toxicity, biodegradability and viability. Further efforts should be made to improve flocculation efficiency of starch as flocculant to take place of complexes of polyacrylamide and $\mathrm{Al}_{2}\left(\mathrm{SO}_{4}\right)_{2}$.

Acknowledgments The authors would like express their thanks to University Grants Commission, New Delhi, India for financial support.

Open Access This article is distributed under the terms of the Creative Commons Attribution License which permits any use, distribution, and reproduction in any medium, provided the original author(s) and the source are credited. 


\section{References}

Amuda OS, Amoo IA, Ajayi OO (2006) Performance optimization of coagulant/flocculant in the treatment of wastewater from a beverage industry. J Hazard Mater 129(1-3):69-72

Babu R, Chaudhuri M (2005) Home water treatment by direct filtration with natural coagulant. J Water Health 3:27-30

Bina B, Mehdinejad MH, Nikaeen M, Movahedian Attar H (2009) Effectiveness of chitosan as natural coagulant aid in treating turbid waters. Iran J Environ Health Sci Eng 6(4):247-252

Blackburn RS (2004) Natural polysaccharides and their interactions with dye molecules: applications in effluent treatment. Environ Sci Technol 38:4905-4909

Buleon A, Colonna P, Planchot V, Ball S (1998) Starch granules: structure and biosynthesis. Int J Biol Macromol 23:85-112

DI Bernardo AS, DI Bernardo L, Frollini E (2009). Influence of the application time on the efficiency of polymer flocculation/ sedimentation. XXVII Inter-American Congress of Sanitary and Environmental Engineering. Annals 2000

Divakaran R, Pillai VN (2002) Flocculation of river silt using chitosan. Water Res 36:2414-2418

Ebeling JM, Sibrell PL, Ogden SR, Summerfelt ST (2003) Evaluation of chemical coagulation/flocculation aids for the removal of suspended solids and phosphorus from intensive recirculating aquaculture effluent discharge. Aquacult Eng 29:23-42

Feisal K, Montarop Y (2010) Chitin research revisited. Mar Drugs $8(7): 1988-2012$

Guibal E (2004) Interactions of metal ions with chitosan-based sorbents: a review. Sep Purif Technol 38:43-74

Hasçakir B (2003) Utilization of natural polyelectrolytes in wastewater treatment. A Thesis Submitted to the Graduate School of Natural and Applied Sciences of DokuzEylül University

Huang C, Chen Y (1996) Coagulation of colloidal particles in water by chitosan. J Chem Technol Biotechnol 66(3):227-232

Jadhav MV, Mahajan YS (2013) Investigation of the performance of chitosan as a coagulant for flocculation of local clay suspensions of different turbidities. KSCE J Civil Eng 17(2):328-334

Jill RP, Chihpin H, Shuchuan C, Ying-Chien C (1999) Evaluation of a modified chitosan biopolymer for coagulation of colloidal particles. Coll Surf Physicochem Eng Asp 147(3):359-364

Jin Y (2005) Use of high resolution photographic technique for studying coagulation/flocculation in water treatment. M.Sc Thesis, University of Saskatchewan, Saskatoon, 22-29

Khoushab F, Yamabhai M (2010) chitin research revisited. Mar Drugs 8(7):1988-2012

Li Q, Kegley L (2005) Assessing the effectiveness and environmental impacts of using natural flocculants to manage turbidity. Oregon Department of Transportation Research Unit, USA

Ma JJ, Li GB, Chen GR, Xu GO, Cai GQ (2001) Enhanced coagulation of surface waters with high organic content by permanganate peroxidation. Water Sci Technol: Water Supply $1: 51-61$

Mackenzie LD, Cornwell DA (1991) Introduction to environmental engineering, 2nd edn. McGraw Hill, New York

Manickavasagan A, Thangavel K (2006) A survey of water consumption and product output from Ten Sago Factories in India. Short Communication. Pertanika J Trop Agric Sci 29(1 \& 2):67-72
Mano JF, Silva GA, Azevedo HS, Malafaya PB, Sousa RA, Silva SS, Boesel LF, Oliveira JM, Santos TC, Marques AP, Neves NM, Reis RL (2007) Natural origin biodegradable systems in tissue engineering and regenerative medicine: present status and some moving trends. J R Soc Interface 4:999-1030

McConnachie GL, Folkard GK, Mtawali MA, Sutherland JP (1999) field trials of appropriate hydraulic flocculation processes. Wat Res 33(6): 1425-1434

Minke R, Blackwell J (1978) The structure of [alpha]-chitin. J Mol Biol 120:167-181

Muzzarelli RAA (1977) Chitin. Pergamon Press, Oxford

Nnaji PC (2012) An investigation of the performance of various coagulants/flocculants in removing the turbidity of coal washery effluents. M. Eng. Thesis, Federal University of Technology, Owerri

Patel H, Vashi RT (2013) Comparison of naturally prepared coagulants for removal of COD and color from textile wastewater. Glob NEST J 15(4):522-528

Qudsieh M, Yassin I (2006) Synthesis, characterization and application of polyacrylamide grafted sago starch for coagulation and flocculation processes. PhD thesis, Universiti Putra Malaysia

Radhakrishnan (1996) Mechanical stirrer for tapioca starch settling tanks. (Unpublished M.E. Thesis, Department of Agricultural Processing, Tamil Nadu Agricultural University, India)

Renaut F, Sancey B, Badot PM, Crini G (2009) Chitosan for coagulation/flocculation processes, an eco-friendly approach. Europ Polym J 45:1332-1348

Renu Y, Garima G (2013) A Review on Indian Sago Starch and its Pharmaceutical Applications. Int J Pharm Life Sci 2(3):99-106

Richter CA (2009) Water: Methods and treatment technology 1st edn Ed Blucher, Sao Paulo, p 333

Rinaudo M (2006) Chitin and chitosan: properties and applications. Prog Polym Sci 31:603-632

Roussy J, Van Vooren M, Dempsey B, Guibal E (2005) Influence of chitosan characteristics on the coagulation and the flocculation of bentonite suspensions. Water Res 39:3247-3258

Ruhsing Pan J, Huang C, Chen S, Chung YC (1999) Evaluation of a modified chitosan biopolymer for coagulation of colloidal particles. Colloids Surf, A 147(3):359-364

Sabuindia (2013) http://www.sabuindia.com/sago1.htm (13 April 2013)

Theodoro JDP, Lenz GF, Zara RF, Bergamasco R (2013) Coagulants and natural polymers: perspectives for the treatment of water. Plast Polym Technol (PAPT) 2(3):55-62

Volk C, Bell K, Ibrahim E, Verges D, Amy G, Lechevaller M (2000) Impact of enhanced and optimized coagulation on removal of organic matter and its biodegradable fraction in drinking water. Water Res 34:3247-3257. doi:10.1016/S0043-1354.00.00033.6

Wang LK, Hung YT, Shammas NK (2005) Physico-chemical treatment processes. Handbook of environmental engineering, vol 3. The Humana Press Inc., Totowa

Yukselen MA, Gregory J (2004) The effect of rapid mixing on the break-up and re-formation of flocs. J Chem Technol Biot 79:782-788. doi:10.1002/jctb.1056

Zikakis JP (1984) Chitin, chitosan, and related enzymes. Academic press 